\title{
Syndrome of polydactyly, cleft lip, lingual hamartomas, renal hypoplasia, hearing loss, and psychomotor retardation: variant of the Mohr syndrome or a new syndrome?
}

\author{
JEAN-FRANÇOIS MATTEI AND SÉGOLÉNE AYMÉ \\ From INSERM U242, Centre de Génétique Médicale, Marseille, France.
}

SUMmARY Three sibs, the proband and two monozygotic twins, have a condition including mental retardation, postnatal somatic retardation, preaxial polydactyly of the feet, bifid third metacarpal, median cleft lip, fatty hamartomas on the dorsum of the tongue, conductive hearing loss, and unilateral or bilateral renal agenesis. This probably autosomal recessive syndrome could be a further example of the condition described by Váradi et al ${ }^{1}$ or a variant of the Mohr syndrome.

Variable expression is a major problem when trying to make diagnoses of rare conditions, unless several affected sibs can be examined and show a consistent spectrum of anomalies. In the oral-facial-digital syndrome II, so-called Mohr syndrome, both variable expressivity of the gene and genetic heterogeneity are now suspected. We describe a family which could be an example of a new oral-facialdigital syndrome, different from the Mohr syndrome and resembling the condition described by Váradi et al. ${ }^{1}$

Received for publication 25 March 1983. Accepted for publication 28 April 1983.

\section{Case reports}

The proband, a boy, was first examined at the age of 6 as part of a systematic survey of institutionalised children. He was severely mentally retarded $(I Q=35)$ with severe growth failure $(-4 \mathrm{SD})$ and oro-facialdigital malformations. His head circumference was normal for his age. He had synophrys (fig 1), a normal nose, short philtrum, thick lips with a minor median cleft lip, normal teeth and palate, thick alveolar ridge, fatty hamartomas on the dorsum of the tongue, which was otherwise normal, no hypertrophy of the frenula, and normal posteriorly

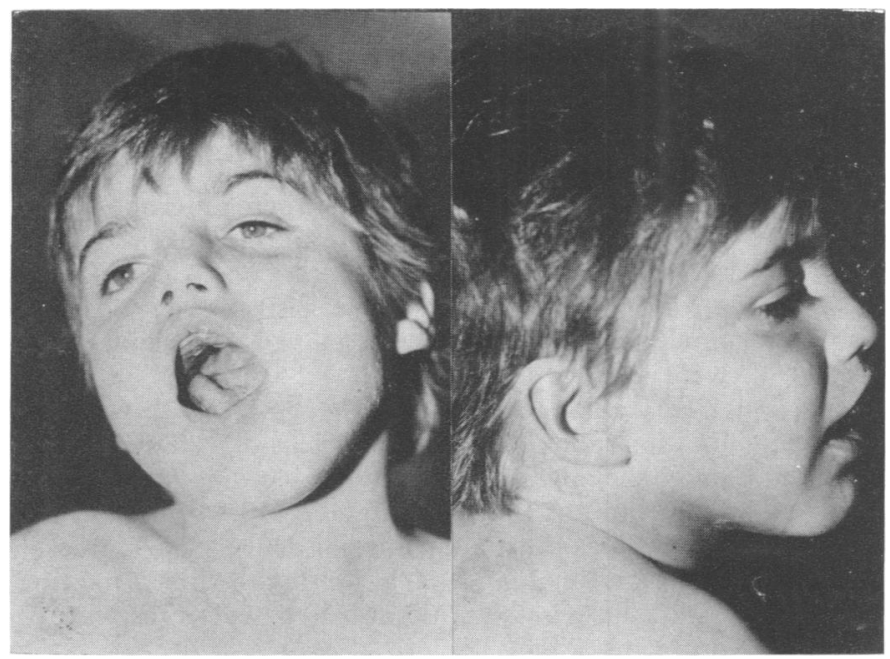

FIG 1 Proband (II.5) at 6 years of age. Note mild median cleft lip, short philtrum, and well-developed chin. 


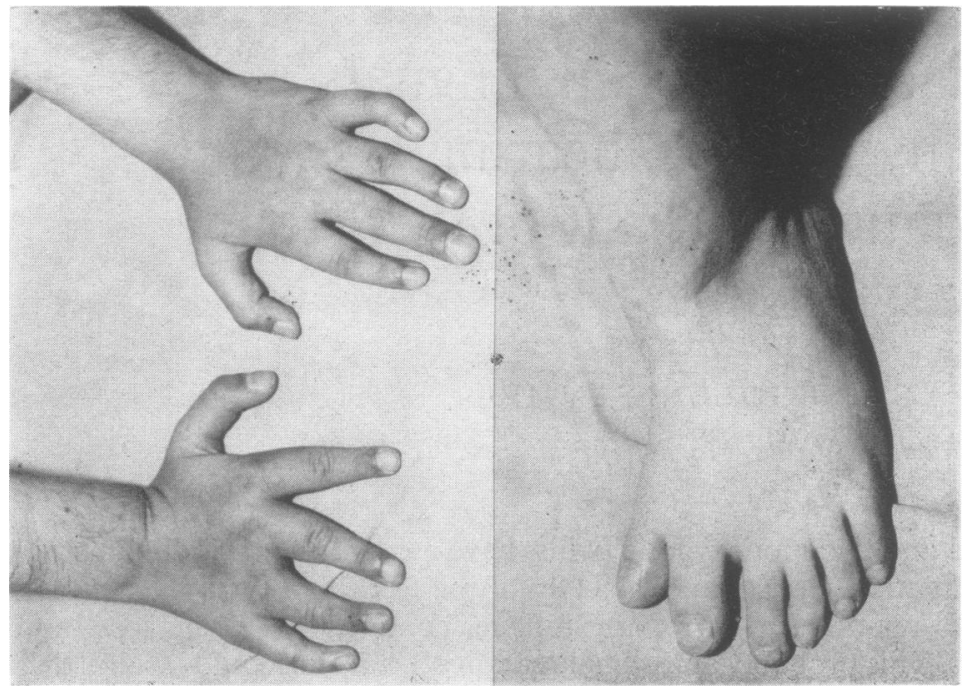

FIG 2 Hands and feet of proband (II.5).

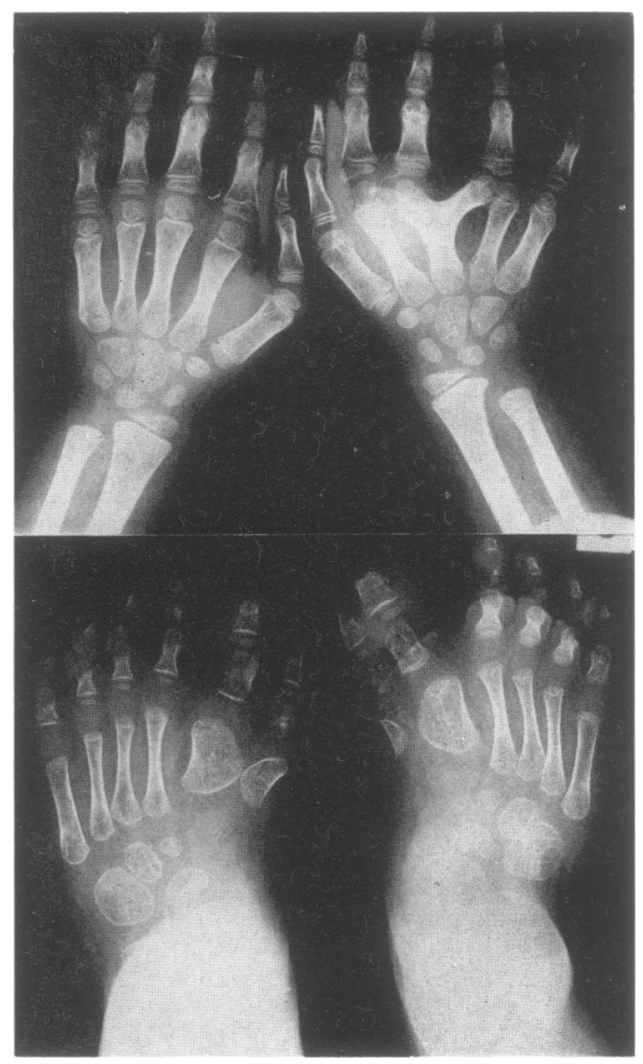

FIG $3 X$-ray of the hands and feet showing bifid third metacarpal bone and hallux duplication.
I

II<smiles>CC(C)C1CCCC1C(C)C</smiles>

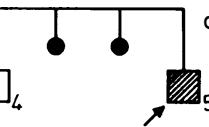

FIG 4 Pedigree of the family.

rotated ears. The limbs showed bilateral fifth finger clinodactyly and preaxial polydactyly of both feet (fig 2). The radiographs showed a thick skull with normal malar bones, maxilla, and mandible, a bifid third metacarpal bone, short second phalanx of all fingers, bilateral hallux duplication (fig 3), and vertebral bodies shortened in their anteroposterior axis. An IVP revealed unilateral renal agenesis. CT scan demonstrated dilated ventricular cavities with $D$ atrophy of the vermis. He also had a bilateral moderate conductive hearing loss. His chromosomes were normal ( $R$ banding).

He was the last child (G6, P4, fig 4) of a 35-year-old mother and unrelated 33-year-old father. The pregnancy was disturbed by bleeding during the first 2 months which was treated with hormones. The 6 patient was born after normal delivery at 42 weeks' gestation weighing $3400 \mathrm{~g}$. During the first 2 months ? of life he was cyanotic and had severe respiratory problems. 
Four years earlier, two monozygotic male twins were born at 34 weeks' gestation and died a few minutes after birth. According to the necropsy report, both had hexadactyly of the hands and feet, talipes equinovarus, and severe bilateral renal hypoplasia with some cystic formations. No orofacial disturbance was mentioned and the father who saw the children says that they certainly had no cleft.

\section{Discussion}

These three sibs have an oro-facio-digital syndrome, inherited as an autosomal or $X$ linked recessive condition, which is quite similar to the syndrome described by Váradi $e t a^{1}$ in seven gypsy patients. They have in common early death in several patients and very severe postnatal mental and somatic retardation in those who survive. Postaxial polydactyly of the feet is common to all patients and the hands have a very peculiar bifid third metacarpal causing polydactyly of the hands. There is no cleft or lobate tongue or multiple frenula. Our patients have unilateral or bilateral renal agenesis, a feature not mentioned by Váradi et al, ${ }^{1}$ but apparently only one of their patients had a necropsy and none an IVP.

The question arises of whether these patients have the Mohr syndrome. ${ }^{2}$ This syndrome usually combines a lobate tongue with or without cleft, cleft palate, hypertrophied frenula, broad nasal root and tip, long philtrum, micrognathia, dystopic canthi, brachy-, syn-, clino-, or polydactyly, moderately short stature, normal intelligence, and moderately impaired conductive deafness. Some patients have a cardiac defect or hypoplastic tibiae or both. Perinatal death is rare in this syndrome.

The main reason for thinking that our patients, as well as those of Váradi et al, ${ }^{1}$ do not have the Mohr syndrome is that there is reasonable consistency within sibships in the two families. Neither our patients nor any of those of Váradi et $\mathrm{l}^{1}$ had a lobate tongue, multiple frenula, or micrognathia, and all of those who were $x$-rayed had a bifid third metacarpal. All those who survived had very severe mental and somatic retardation. The survival rate is low.

We suggest that these patients have a genetic condition distinct from the oral-facial-digital syndrome II. Renal agenesis is probably a major feature of this new syndrome. This would be the second split in this entity after the report by Baraitser et $\mathrm{l}^{3}$ of a new distinct type.

\section{References}

1 Váradi V, Szabó L, Papp Z. Syndrome of polydactyly, cleft lip/palate or lingual lump, and psychomotor retardation in endogamic gypsies. $J$ Med Genet 1980;17: 119-22.

2 Gorlin RJ, Pindborg JJ, Cohen MM. Syndromes of the head and neck. 2nd ed. New York: McGraw Hill, 1976: 568-70.

3 Baraitser M, Burn J, Fixsen J. A female infant with features of Mohr and Majewski syndromes: variable expression, a genetic compound, or a distinct entity? J Med Genet 1983;20:65-7.

Correspondence and requests for reprints to Professor J-F Mattei, INSERM U242, Hôpital d'Enfants de la Timone, 13385 Marseille Cedex 5, France. 